\title{
Clues to finding correlates of risk/protection for HIV-1
}

\section{vaccines [version 1; peer review: 1 not approved]}

\author{
Marian P. Laderoute (iD) \\ Immune System Management Clinic \& Lab, Ottawa, ON, K1S 5R5, Canada
}

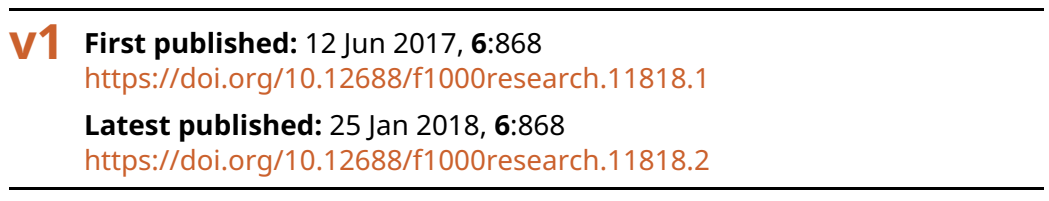

\section{Abstract}

Almost a decade later, we still do not understand why in the STEP trial (2008), males with pre-existing antibodies to the Ad5 vector were associated with initial increased risk of HIV-1 acquisition. Similarly, we have little conclusive evidence of why in the RV144 trial (2009), vaccination with the ALVAC-HIVIAIDSVAX B/E was associated initially with almost a $60 \%$ vaccine efficacy at year one, which waned over 42 months to $31.2 \%$, and where females were more protected than males. Based on the literature and trial outcomes, it was deduced that the elusive correlate of risk/protection may pertain to a novel, potent, innate protector mechanism launched by alternatively activated macrophages, which is probably induced by viruses and female steroid hormones. It was also suggested this mechanism was not likely amenable to discovery using standard or traditional approaches. A plausible, candidate mechanism was identified with these characteristics, namely the production of human endogenous retrovirus-K102 (HERV-K102) particles, which occurs in, and generates, foamy macrophages in vitro. Accumulating clinical, biological and phylogenetic evidence supports its role in the antagonism of HIV-1 replication and/or in the prevention of HIV-1 acquisition. Thus, it will be important to examine HERV-K102 particle production, increased integration and envelop antibody production as candidate correlates of protection in HIV-1 vaccine trials, as well as in HIV-1 highly exposed seronegative cohorts and elite controllers. The results of such efforts may have important ramifications for the HIV-1 cure in addition to vaccines.

\section{Keywords}

HIV-1, novel, correlates of protection, HIV-1 vaccines, HERV-K HML-2, HERV-K102, foamy macrophages, innate immunity

\section{Open Peer Review \\ Approval Status? ? \\ 1 2 \\ version 2 \\ (revision) \\ $25 \operatorname{Jan} 2018$ \\ version 1 \\ 12 Jun 2017

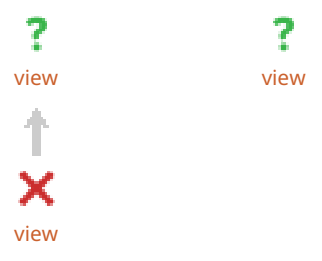 \\ 1. Patricia E Fast ID, International AIDS \\ Vaccine Initiative-New York, New York, USA \\ Stanford University School of Medicine, \\ Stanford, USA \\ 2. Robert Gallo, University of Maryland, \\ Baltimore, USA \\ Any reports and responses or comments on the article can be found at the end of the article.}


Corresponding author: Marian P. Laderoute (hervk102@bell.net)

Author roles: Laderoute MP: Conceptualization, Data Curation, Formal Analysis, Funding Acquisition, Investigation, Methodology, Project Administration, Resources, Software, Supervision, Validation, Visualization, Writing - Original Draft Preparation, Writing - Review \& Editing

Competing interests: No competing interests were disclosed. While the author was named as one of the inventors in patent applications for the discovery of HERV-K102 as a replication competent foamy-like virus and for envelope specific antibodies either of which may have applications in the field of infectious diseases, by policy at the Public Health Agency of Canada, public servants have no rights nor entitlements.

Grant information: The author declares that no grants were involved in supporting this work. However, unpublished studies cited were previously supported by funding from the Blood Safety Program at the Public Health Agency of Canada and in part by an Innovative Research grant from the Office of the Chief Scientist at Health Canada.

Copyright: ( 2017 Laderoute MP. This is an open access article distributed under the terms of the Creative Commons Attribution License, which permits unrestricted use, distribution, and reproduction in any medium, provided the original work is properly cited.

How to cite this article: Laderoute MP. Clues to finding correlates of risk/protection for HIV-1 vaccines [version 1; peer review: 1 not approved] F1000Research 2017, 6:868 https://doi.org/10.12688/f1000research.11818.1

First published: 12 Jun 2017, 6:868 https://doi.org/10.12688/f1000research.11818.1 


\section{Introduction}

It has been recently stated that immune correlates of risk/protection for HIV-1 vaccines must be complex and/or reliant on the right combination of multiple types of immune responses, as correlates of protection have eluded investigators (Tomaras \& Plotkin, 2017). However, the relatively low rates of acquisition of HIV-1 per exposure at less than 1 in 1000 for heterosexual transmission (Becerra et al., 2016), may instead argue that defense against HIV-1 in humans possibly involves a simpler and more potent mechanism than what has yet been elucidated or appreciated. Indeed, that a new scientific paradigm may be needed to advance the development of the HIV-1 vaccine has been recently proclaimed (Esparza, 2015). What then can we currently deduce about the characteristics of this unknown correlate of risk/protection, such as from the two informative HIV-1 preventative vaccine trials: one associated with increased HIV-1 transmission, known as the STEP trial (Buchbinder et al., 2008), while the RV144 trial that was associated with decreased HIV-1 transmission (Rerks-Ngarm et al., 2009)?

\section{The elusive correlate is likely launched by activated macrophages}

In any immune response, innate and/or adaptive, activated macrophages control the response. Accordingly, it follows that any risk or protection associated with HIV-1 vaccines must then relate to a key and so far, ill-defined macrophage activation pathway. Moreover, in HIV-1 acquisition, the transmitting/founder strains are generally CCR5-tropic and target macrophages (reviewed in Borggren \& Jansson, 2015). Together these findings point to the likelihood that there exists a novel macrophage-based defense mechanism that itself determines whether HIV-1 will be acquired.

The Ad5 vector used in the STEP trial, highly targets liver Kupffer cells, which represent about $80-90 \%$ of the macrophages in the body (Khare et al., 2011). In the STEP trial, male uncircumcised participants with Ad5 antibodies were significantly at increased risk of transmission compared with those without vector antibodies (Buchbinder et al., 2008). This suggests that at the interface of the Ad5 vector with macrophages, the presence of bound Ad5 antibodies enriched in the local milieu may have somehow blocked the induction of the putative, gatekeeper/defense mechanism of macrophages. A possible candidate mechanism for this interference by antibody is tuftsin, a short peptide consisting of the sequence TKPR, which is released from bound $\mathrm{IgG}$ and is known to inhibit macrophage activation at higher concentrations, while at lower levels, it augments macrophage activation (Siemion \& Kluczyk, 1999). Thus, it appears to be plausible that higher risk participants (uncircumcised men) with pre-existing Ad5 antibodies injected with an Ad5 vector could have experienced inhibition of the putative, novel macrophage defense mechanism such as by the local generation of tuftsin, thereby explaining their increased risk.

\section{Other salient clues to the characteristics of the novel host protection mechanism revealed from the informative HIV-1 vaccine trials}

Another important clue relates to gender. In the STEP trial, women were notably at decreased risk of HIV-1 acquisition when compared with males (Buchbinder et al., 2008), whereas in the RV144 trial protection against HIV-1 acquisition was more evident in females than males (about 1.5-fold better) (Rerks-Ngarm et al., 2009). Together these findings suggest the novel, macrophage based protection mechanism is likely induced by female hormones.

That the risk/protection was only temporary in either trial, generally lasting 6 to 12 months after the last immunization (Buchbinder et al., 2008; Rerks-Ngarm et al., 2009), was consistent with an innate rather than adaptive immunity mechanism. In addition, following HIV-1 acquisition, the levels of CD8 and CD4 positive, CD38 positive, DR positive activated $\mathrm{T}$ cells are well recognized progression markers (Deeks et al., 2004), indicating adaptive immunity is unlikely to provide significant protection against HIV-1 replication. Accordingly, the key protection mechanism must be innate, but this does not necessarily rule out important contributions of intrinsic factors, such as APOBEC, which may antagonize HIV-1 replication and may also be upregulated with alternative activation of macrophages (Colomer-Lluch et al., 2016; Hartmann, 2017).

Since both risk (Buchbinder et al., 2008) and protection (Rerks-Ngarm et al., 2009) were found with viral vectored vaccines, and not in the VAX003 and VAX004 HIV-1 vaccine trials, which instead involved proteins and adjuvants (reviewed in Shin, 2016), this raises the likelihood that viruses in general may activate the undefined macrophage-based defense mechanism, in addition to HIV-1.

Overall, these observations point to the existence of a novel, potent innate HIV-1 protection mechanism induced by viruses and female hormones, which is launched by activated macrophages, possibly using alternative pathways, and that this activation may be sensitive to inhibition by locally bound antibodies, for example by tuftsin. Moreover, despite a considerable effort both inside and outside of the trials, convincing immune correlates of risk or prevention against HIV-1 have yet to be revealed. This failure raises the following notions about the mechanism. It is likely not addressed by traditional in vitro culture methods, not discoverable using conventional detection methods on participant samples, including microarray and genome wide association studies, nor is it likely present in the rhesus macaque. The critical question becomes, has such a novel, innate, potent, defense mechanism unique to human activated macrophages and difficult to study under standard conditions, been previously described?

Surprisingly, the answer to this may be, yes.

A novel, human-specific, foamy macrophage protection mechanism serendipitously discovered and relevant to protection against HIV-1 acquisition

A novel, innate, viral defense mechanism unique to humans, associated with the production of foamy macrophages in vitro (Figure 1) was serendipitously discovered by scientists working at the Public Health Agency of Canada about 10 years ago, and fulfills all the above criteria for a defense mechanism launched by alternatively activated macrophages (Laderoute et al., 2007; Laderoute et al., 2015; Laderoute, 2015). 


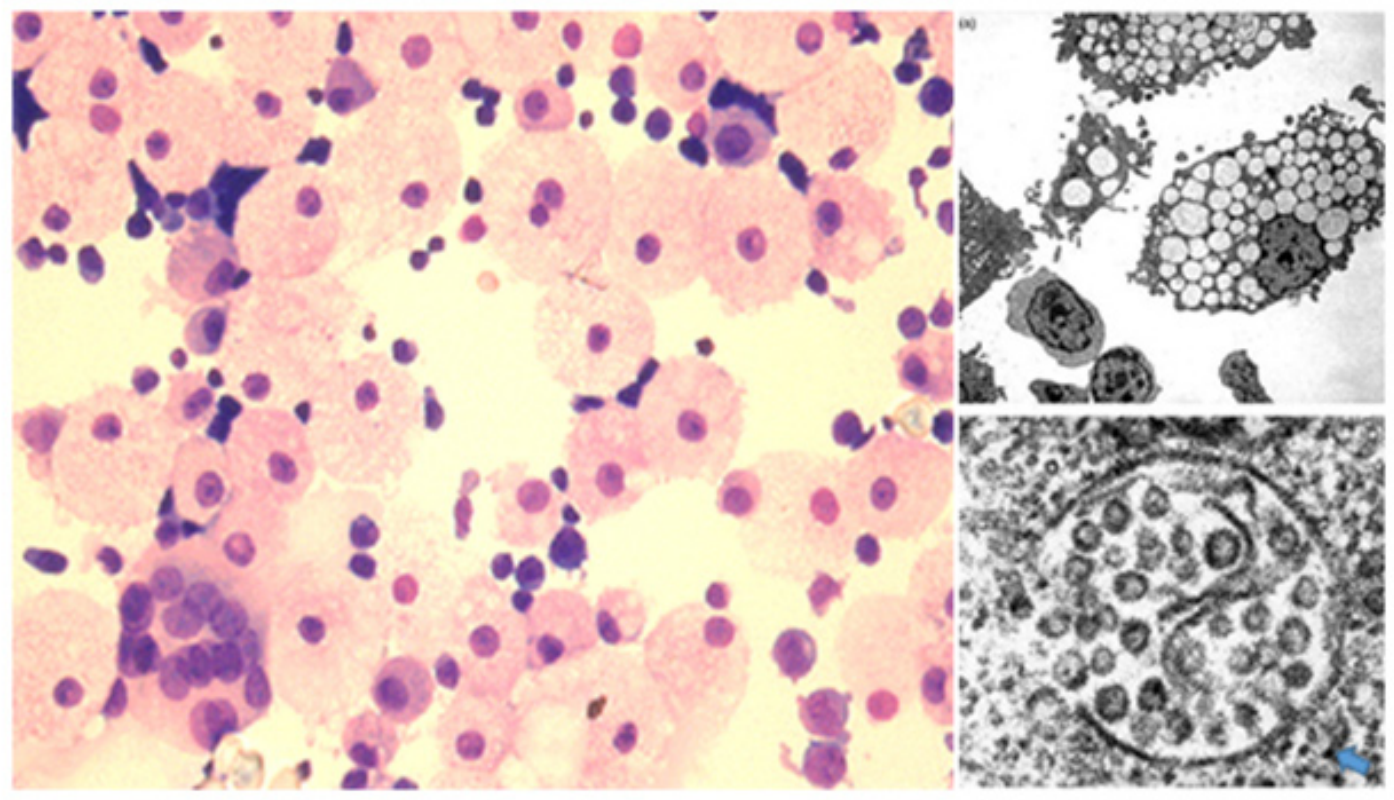

Figure 1. Spontaneous foamy macrophage generation associated with HERV-K102 particle production in cord blood mononuclear cells (CB) when cultured in IMDM. Left panel, $\mathrm{H}$ and E stain of day 11 cultured CB prepared by cytospin. Right panels, electron micrographs show vacuoles in the foamy macrophages contain large numbers of immature particles with envelope spikes. Blue arrow points to the cytoplasmic capsid assembly outside of the vacuole, typical of foamy retroviruses (Hütter et al., 2013). Left panel reproduced under a CC BY- NC 4.0 license (Laderoute et al., 2015). Right panels reproduced with permission from the AIDS journal (Laderoute et al., 2007).

Importantly, this also includes initial evidence that it was associated with protection against HIV-1 acquisition in a female, HIV-1 highly exposed seronegative cohort (HESN), at the level of about $80 \%$ of the tested cohort (Laderoute et al., 2015). Moreover, protection in the infamous Nairobi HESN cohort (Fowke et al., 1996) is known to be temporary, as resistance to HIV-1 acquisition dwindled as early as 6 months to a year following abstinence from sex trade work (Kaul et al., 2001). Thus, this novel foamy macrophage mechanism, which might be implicated in the Nairobi HESN cohort, seems to meet a key criterion of temporary activity and waning after 6 months.

\section{A novel human, endogenous foamy-like virus generates foamy macrophages in vitro and may be remarkably potent}

This putative defense mechanism launched by activated foamy macrophages in vitro (Figure 1) was characterized as human endogenous retrovirus K102 (HERV-K102, GenBank accession \# AF164610) (Laderoute et al., 2015). HERV-K102 is an endogenous retrovirus unique to humans (Subramanian et al., 2011), and is the only HERV-K HML-2 group member which has been shown to be replication competent in vivo and as associated with viremia (Laderoute et al., 2007). As extensively reviewed elsewhere (Laderoute et al., 2015), it has hallmark features of nonpathogenic, foamy retroviruses. Like foamy viruses, its genomes are predominantly DNA rather than RNA (Laderoute et al., 2007) and replication involves budding into vacuoles rather than the cell surface, which renders cells foamy (Figure 1). It is important to note that the particles are released by cell lysis of the foamy macrophages and that foamy macrophages do not express HERVK102 envelope at the cell surface (unpublished studies; Marian Laderoute). When cord blood mononuclear cells (CB) were cultured in IMDM rather than RPMI media, HERV-K102 spontaneously replicated, generating high levels of foamy macrophages (Laderoute et al., 2007; Laderoute et al., 2015). Others have similarly reported the induction of foamy macrophages when CB was cultured in IMDM (Stec et al., 2007). HERV-K102 appears to be the only HERV-K HML-2 element so far shown to be naturally replication competent in vitro (Laderoute et al., 2015) and in vivo (Laderoute et al., 2007).

HERV-K102 particles released by freeze-thaw cycles of cultured $\mathrm{CB}$ cells, induced rapid and complete cell lysis of MRC-5 cells at 24 hours, which was not demonstrated for other cell lines tested (unpublished study; Marian Laderoute). This was expected as foamy viruses are well known to produce rapid cell lysis of some, but interestingly, not all fibroblastic cell lines (Linial, 2001). However, it remains to be determined which cell death pathway (Duprez et al., 2009) might mediate this remarkably rapid cell lysis, if integration is needed, and more critically, if HERV-K102 particles might similarly lyse HIV-1 infected cells. It is notable that HERV-K102 also appeared to be strongly induced in vivo increasing from no particles detected to $2.55 \times 10^{11}$ cDNA containing particles per $\mathrm{ml}$ of plasma within 84 hours (unpublished study; 
Marian Laderoute). High levels of particles at $10^{10}$ to $10^{12}$ per ml of plasma were frequently found in patients viremic for various bloodborne pathogens, but maximum levels in HIV-1 patients were notably 7 to 8 log-fold downmodulated in comparison (Laderoute et al., 2007). It can be estimated from previously reported data that in HIV-1 patients there may only be on average about 8,200 DNA containing particles per ml of plasma corresponding to HERV-K102 (Laderoute et al., 2007), which has been substantiated by others but as demonstrated by the detection of excess HERV-K HML-2 transmembrane envelope DNA but not RNA sequences on isolated particles as compared with normal healthy controls. (Bhardwaj et al., 2014). It should also be noted that two groups have reported that HERV-K HML-2 particles with RNA genomes were not demonstrable in HIV-1 patients (Bhardwaj et al., 2014; Karamitros et al., 2016), consistent with the notion that HERV-K102 transcripts in particles are predominantly or exclusively DNA (Laderoute et al., 2007). Taken together these results may suggest only HERV-K102 particles with DNA genomes are significantly produced in HIV-1 patients, but this needs to be more carefully addressed. Thus, overall, based on rapid induction, the high levels of particles that can be produced both in vitro (Figure 1) and in vivo (Laderoute et al., 2007), and potentially swift cell kill by particles (unpublished study; Marian Laderoute), HERV-K102 particles could comprise a potent innate immune mechanism launched by foamy macrophages. However, upon HIV-1 acquisition, HERV-K102 particle production and/or release appear to be strongly inhibited.

\section{HERV-K102/HML-2 expression associated with HIV-1 infection or exposures to HIV-1}

In vitro, and despite suboptimal conditions by culture of the cells in RPMI, several research groups have confirmed that HERV-K102 is induced by HIV-1 (Brinzevich et al., 2014; Vincendeau et al., 2015). Moreover, HERV-K102 may be the only human specific, full length HML-2 element induced by HIV-1 and/or Tat (GonzalezHernandez et al., 2012). While the envelope of HERV-K18 and a consensus sequence for HERV-K HML-2 were able to pseudotype HIV-1 virions, interestingly HERV-K102 did not (Brinzevich et al., 2014; Lee \& Bieniasz, 2007). That HIV-1 may be pseudotyped by HML-2 envelope raises the notion that such pseudotyped particles could help explain, in part, the altered tropism for macrophages bearing the CCR5 coreceptor, which is commonly used by transmitting/founder strains (Borggren \& Jansson, 2015). If this is indeed the case, it would also help explain why vaccination against HIV-1 envelope generally fails to prevent HIV-1 acquisition (reviewed in Shin, 2016), or why passive immunization with HIV-1 envelope specific, broadly neutralizing envelope antibodies failed to significantly control viremia upon antiretroviral treatment interruption (Bar et al., 2016; Caskey et al., 2017).

The mean HERV-K102 pol copy number in the genomes of the HESN, as demonstrated on DNA extracted from plasma, was elevated about 5-fold above the genomic levels of normal healthy adults $(\mathrm{p}<0.0005)$ (Laderoute et al., 2015). This is consistent with high integration levels reported for foamy viruses in hematopoietic cell lines (Meiering et al., 2000). This implied very high HERV-K102 particle production likely occurred in the HESN cases. In direct contrast, there was no evidence for increased mean genomic copy number above normal healthy controls for North American individuals already infected with HIV-1, irrespective of their use of anti-retroviral therapy (Laderoute et al., 2015). However, evidence of the activation of this macrophage-based defense system was demonstrated in about $96 \%$ of HIV-1 patients which includes particles and/or HERV-K102 surface unit envelope specific antibodies (post hoc analysis, Laderoute et al., 2007). Thus, as might be expected, individuals protected against HIV-1 acquisition may produce high numbers of HERV-K102 particles reflected by increased integration, but upon its acquisition, HERV-K102 particle production was strongly downmodulated with no evidence of increased integration of HERV-K102 sequences (Laderoute et al., 2007; Laderoute et al., 2015).

In potential substantiation of an important role of HERV-K102 in the control of HIV-1 replication, HERV-K HML-2 gag and envelope RNA expression in peripheral blood mononuclear cells (PBMCs) in HIV-1 patients were shown to be inversely correlated with $\mathrm{T}$ cell activation markers (Ormsby et al., 2012). Since it is known that activated T cells correlate with HIV-1 progression (Deeks et al., 2004), this implies HML-2 expression generally, and by proxy HERV-K102 activation, may antagonize HIV-1 replication. This argument is further strengthened by recent evidence that suggests the newer HERV-K HML-2 elements containing LTR5Hs (which include HERV-K102) are upregulated in CD11c+ myeloid dendritic cells isolated from HIV-1 patients, whereas, in normal healthy controls, the older LTR5A and LTR5B bearing HML-2 elements prevailed (Young et al., 2014).

Both antibodies and T cell responses to HERV-K HML-2 and/or HERV-K102 envelope have been demonstrated in HIV-1 and breast cancer patients (reviewed in Laderoute et al., 2015). A $\mathrm{T}$ cell clone isolated from an elite controller, which recognized a peptide identical to HERV-K102 envelope, was shown in vitro to specifically eliminate cells infected with various HIV and SIV strains (Jones et al., 2012). Remarkably, a monoclonal antibody made to HERV-K102 envelope could directly provoke apoptosis in vitro and in vivo (Wang-Johanning et al., 2012). This might suggest that the expression of HML-2 envelope on the surface of virally infected or transformed cells, but which is not found on normal cells, plays a more active role in innate host protection than merely as a surrogate marker. These findings may also further document the unexpected potency of this innate protector mechanism against HIV-1, which unlike adaptive immunity, remarkably functions irrespective of the hypervariability of HIV-1, quasi-species and/or strains of HIV-1 or lentivirus involved.

\section{Gender differences in HERV-K HML-2 activation}

In terms of other characteristics of the defense mechanism deduced earlier from the informative HIV-1 vaccine clinical trials, combination female steroid hormones (estrogen then progesterone) have been shown to stimulate the expression of HERV-K HML-2 (Ono et al., 1987). In a recent meta-analysis, while the use of various progestins for oral contraception were associated with a significantly increased adjusted hazard ratio of HIV-1 acquisition over women who did not use contraceptives, the combined oral contraceptive was not (Morrison et al., 2015). This is consistent 
with the notion that women of child-bearing age (and not on progestins), may be more protected against HIV-1 acquisition compared with male counterparts possibly through regular, monthly induction of the HERV-K102 protector system by combined estrogen and progesterone.

\section{HERV-K102 particle production is not addressed by standard methodology}

The identification and elucidation of correlates of protection against HIV-1 have been challenging. Overall the failure to identify HERV-K102 particles pertains largely to the notion that its presence is, more often than not, overlooked or not addressed by standard methodological approaches. For example, because HERV-K102 is unique to humans (Subramanian et al., 2011), it is absent from animal models, such as macaques and rodents, which are commonly used for vaccine or immunological investigations. In addition to HERV-K102 and HML-2 being inhibited when PBMCs or $\mathrm{CBs}$ are cultured in the more traditional RPMI media invariably used by immunologists (Argaw-Denboba et al., 2017; Laderoute et al., 2015), HERV-K102 activation is also blocked by the depletion of CD14 + cells from PBMC, and also by the addition of PHA and IL-2 to cultures performed in IMDM (unpublished studies; Marian Laderoute). Accordingly, it may not be a co-incidence that the conditions that block HERVK102 particle production in vitro are those that instead are commonly employed to demonstrate HIV-1 infectivity, such as purified T cells activated with PHA and IL-2 cultured in RPMI. Indeed, these observations would be consistent with the possibility that HERV-K102 particles may antagonize HIV-1 replication in vitro; however, importantly this needs to be directly examined.

The detection of the presence of HERV-K102 particles also eludes other common approaches utilized for investigations. For example, detection of particles in plasma requires an alternative isolation strategy seldom employed by retrovirologists. It requires DNA and not RNA isolation from plasma (Laderoute et al., 2007), where the use of DNAse would be contraindicated. As well, genome wide association studies and microarray analysis typically exclude highly repetitious sequences (Baranzini et al., 2010; Held et al., 2003, respectively) to which this element belongs. Accordingly, HERV-K102 particle production appears to have eluded the field due to the difficulty in demonstrating its presence using standard or traditional approaches.

\section{Tuftsin may modulate HERV-K102 DNA production in vitro}

Relevant to the increased risk of HIV-1 acquisition related to Ad5 antibodies in the STEP trial (Buchbinder et al., 2008), at a high concentration $(2 \mathrm{mg} / \mathrm{ml})$, tuftsin inhibited the production of HERV-K102 DNA in cultured CB by $53 \%$, while at a lower concentration $(200 \mathrm{ng} / \mathrm{ml})$, tuftsin enhanced the replication of HERV-K102 pol containing DNA over normal genomic levels by 237\% (unpublished study; Marian Laderoute). Thus, it seems as a protector mechanism launched by alternatively activated macrophages, HERV-K102 particle production might be subject to modulation by tuftsin and thus possibly relevant to the adverse outcomes of the STEP trial. Clearly, further investigation of the mechanisms of how pre-existing antibodies were associated with adverse outcomes in the STEP trial appears to be warranted.

\section{HERV-K HML-2 activity has been phylogenetically associated with decreased integration of orthoretroviruses in hominins}

Accumulating phylogenetic evidence is consistent with a potential role of HERV-K HML-2 in limiting invasion by orthoretroviruses (Magiorkinis et al., 2015). Ancestral HML-2 elements emerged about 10.3 million years ago (Mya) (Subramanian et al., 2011). There has been a striking decline of insertions of ERVs in the last $10 \mathrm{My}$ in the genomes of all sequenced hominids (great apes and gibbons), but not in old world monkeys (baboons and macaques), particularly regarding HERV-H (Magiorkinis et al., 2015). HERV-H makes up $88 \%$ of all the ERV integrations into the human genome in the last $30 \mathrm{My}$ and became extinct over the past $10 \mathrm{My}$. HERV-H is a gammaretrovirus, which integrated around 45 to 60 Mya and has about 962 copies in the human genome (Chuong et al., 2016). HERV-K, with 10 groups in the clade, only one of which is HML-2, on the other hand, entered the genome of ancestral catarrhines about 32 to 44 Mya, after the split from New World monkeys and before the split of hominids from the Old World monkeys (Kim \& Han, 2015). The sister lineages of HERV-K in most other catarrhines appear to have become extinct. Most remarkably, the HERV-K HML-2 group in humans is the only HERV-K that has continued to replicate since the origin of the catarrhines (Magiorkinis et al., 2015).

Accordingly, since phylogenetic evidence supports an association of HERV-K HML-2 activity with protection against integration of orthoretroviruses, this may help substantiate the claim that modern day HERV-K102 particles, along with expression of proteins from other HML-2 elements, might antagonize HIV-1 replication and/or prevent its acquisition.

\section{The origins of HERV-K102 in humans}

Somewhat ironically, humans apparently acquired the HERVK102 defense mechanism possibly between 500,000 and up to 2 Mya (Romano et al., 2006; Subramanian et al., 2011), from the same source of the modern HIV-1 pandemic strain; namely, chimpanzees.

The Homo-Pan split has been estimated at 6.6 Mya (Magiorkinis et al., 2015) or earlier at 7-8 Mya (Langergraber et al., 2012). As mentioned, the HERV-K HML-2 elements originated in primates about 10.3 Mya and the CERV-K102 sequence (DQ112149), which is $97 \%$ identical to HERV-K102, was estimated to have integrated into chimpanzees at a non-orthologous position about $10(+/-3.3)$ Mya (Romano et al., 2006). Lentiviruses may have been active in primates since the divergence of chimpanzees and humans (Katzourakis et al., 2007; Sawyer et al., 2004). Moreover, it has 
been suggested the ancestor to HIV-1 may have arisen in chimpanzees about 4 Mya (Gifford, 2012). Since, it has been reported that subsets of chimpanzees with chronic HIV-1 infection showed progression analogous to humans, including greater expression of CD38 in CD8+ HLA-DR+ T cells (O'Neil et al., 2000), this raises the notion that an HERV-K102 ancestor, as a potential antidote for HIV-1 infection may have been selected through evolution in chimpanzees before it was acquired by humans. Accordingly, it is possible over about a 2 to 3.5 million-year window or longer, the HERV-K102 ancestor may have adapted to an HIV-1 like ancestor lentiviruses in chimpanzees prior to its acquisition by humans.

\section{Conclusion}

This inquiry has led to the notion that HERV-K102 particle production, which generates foamy macrophages, appears to fulfil the requirements of a deduced candidate correlate of protection against HIV-1 acquisition. Moreover, this candidacy has been strengthened by biological, clinical and phylogenetic evidence, including that which implies HERV-K102 particles may be associated with protection against HIV-1 acquisition. That conversely, acquisition of HIV-1 would be associated with significantly log-lower levels of
HERV-K102 particles, would be anticipated and was observed. Given also the preliminary evidence that tuftsin could block the replication of HERV-K102 in vitro, suggests the blocking of the same mechanism, such as by Ad5 antibodies in the STEP trial shown in males at higher risk, could plausibly account for the increased risk observed in this informative trial. Finally, that the host source of this remarkable innate protection mechanism appears to be the same as that for pandemic strains of HIV-1 would strengthen its authenticity, especially given the likelihood of millions of years of co-evolution of HERV-K102 and HIV-1 in chimpanzees. Overall, the available evidence substantiates that a special antagonistic relationship exists between HIV-1 and a foamy-like virus, HERV-K102.

Accordingly, it will be extremely important to prioritize the testing of human endogenous retrovirus K102 (HERV-K102) particle production, integration, and/or envelope specific antibody production to prove or disprove it as a correlate of risk/protection on actual STEP and RV144 clinical trial participants (Figure 2). Exploratory studies in other HESN cohorts and in elite controllers may also serve to further strengthen the correlation. No less significantly, the clinical ramifications of pseudotyping of HIV-1 virions by HML-2

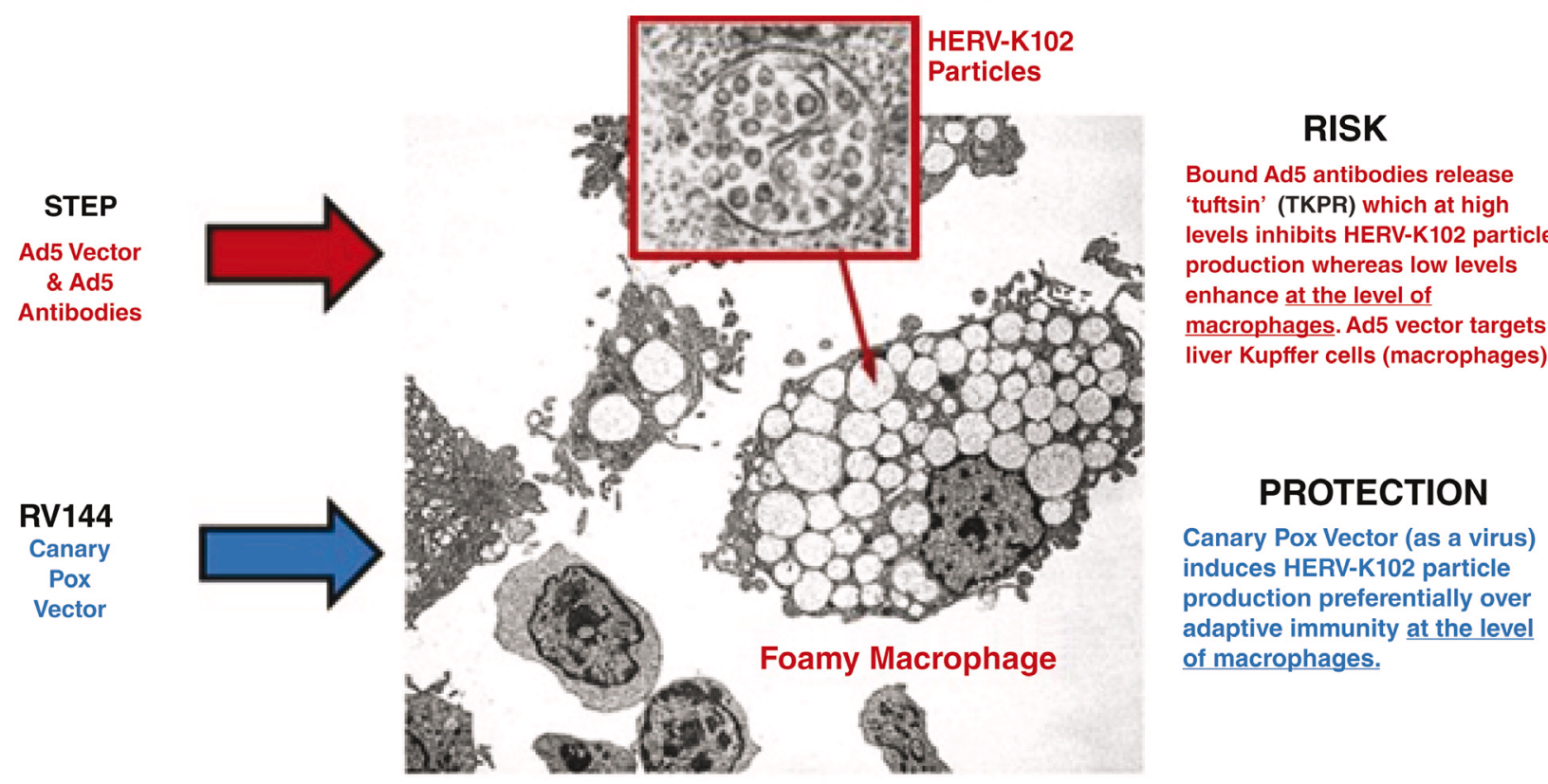

\section{ALTERNATIVE OUTCOMES OF HIV-1 TRIALS OF SIGNIFICANCE: (Control of outcome at the level of macrophages)}

Figure 2. Hypothesized working model of outcomes of the STEP and RV144 trials based on HERV-K102 particle blockage or induction, respectively. Adapted from Figure 1. Note that in the STEP trial, in addition to Ad5 antibodies, Th1 cytokines, such as might be released by Ad5 or HIV-1 antigen responsive T cells, could potentially also block HERV-K102 particle production in macrophages since PHA with IL-2 blocked HERV-K102 particle production in vitro (unpublished study; Marian Laderoute). Consistent with this notion, lower serum levels of IL-2, IFN- $\gamma$, and GM-CSF were recently demonstrated in a cohort of HESN over HIV-1 unexposed controls (Jaumdally et al., 2017), and IFN- $\gamma$ levels were higher in HIV-1 positive over HIV-1 negative individuals (Yong et al., 2016). 
envelope needs to be addressed as it may also help explain in part the failed vaccine and cure attempts.

\section{Competing interests}

No competing interests were disclosed. While the author was named as one of the inventors in patent applications for the discovery of HERV-K102 as a replication competent foamy-like virus and for envelope specific antibodies either of which may have applications in the field of infectious diseases, by policy at the Public Health Agency of Canada, public servants have no rights nor entitlements.

\section{Grant information}

The author declares that no grants were involved in supporting this work. However, unpublished studies cited were previously supported by funding from the Blood Safety Program at the Public Health Agency of Canada and in part by an Innovative Research grant from the Office of the Chief Scientist at Health Canada.
Argaw-Denboba A, Balestrieri E, Serafino A, et al:: HERV-K activation is strictly required to sustain $C D 133+$ melanoma cells with stemness features. $J$ Exp Clin Cancer Res. 2017; 36(1): 20.

PubMed Abstract | Publisher Full Text | Free Full Text

Bar KJ, Sneller MC, Harrison LJ, et al.: Effect of HIV antibody VRC01 on viral rebound after treatment interruption. N Engl J Med. 2016; 375(21): 2037-2050. PubMed Abstract | Publisher Full Text | Free Full Text

Baranzini SE, Mudge J, van Velkinburgh JC, et al.: Genome, epigenome and RNA sequences of monozygotic twins discordant for multiple sclerosis. Nature. 2010; 464(7293): 1351-1356.

PubMed Abstract | Publisher Full Text | Free Full Text

Becerra JC, Bildstein LS, Gach JS: Recent Insights into the HIV/AIDS Pandemic. Microb Cell. 2016; 3(9): 451-475.

PubMed Abstract | Free Full Text

Bhardwaj N, Maldarelli F, Mellors J, et al:: HIV-1 infection leads to increased transcription of human endogenous retrovirus HERV-K (HML-2) proviruses in vivo but not to increased virion production. J Virol. 2014; 88(19): 11108-11120. PubMed Abstract | Publisher Full Text | Free Full Text

Borggren M, Jansson M: The evolution of HIV-1 interactions with coreceptors and mannose C-type lectin receptors. Prog Mol Biol Trans/ Sci. 2015; 129: $109-140$.

PubMed Abstract | Publisher Full Tex

Brinzevich D, Young GR, Sebra R, et al:: HIV-1 interacts with human endogenous retrovirus K (HML-2) envelopes derived from human primary lymphocytes. $J$ Virol. 2014; 88(11): 6213-6223.

PubMed Abstract | Publisher Full Text | Free Full Text

Buchbinder SP, Mehrotra DV, Duerr A, et al: Efficacy assessment of a cell-mediated immunity HIV-1 vaccine (the Step Study): a double-blind, randomised, placebo-controlled, test-of-concept trial. Lancet. 2008; 372(9653): 1881-1893.

PubMed Abstract | Publisher Full Text | Free Full Text

Caskey M, Schoofs T, Gruell H, et al:: Antibody 10-1074 suppresses viremia in HIV-1-infected individuals. Nat Med. 2017; 23(2): 185-191.

PubMed Abstract | Publisher Full Text

Chuong EB, Elde NC, Feschotte C: Regulatory evolution of innate immunity through co-option of endogenous retroviruses. Science. 2016; 351(6277): 1083-1087.

PubMed Abstract | Publisher Full Text | Free Full Text

Colomer-Lluch M, Gollahon LS, Serra-Moreno R: Anti-HIV factors: targeting each step of HIV's replication cycle. Curr HIV Res. 2016; 14(3): 175-182. PubMed Abstract | Publisher Full Text

Deeks SG, Kitchen CM, Liu L, et al:: Immune activation set point during early HIV infection predicts subsequent $\mathrm{CD}^{+}{ }^{+} \mathrm{T}$-cell changes independent of viral load. Blood. 2004; 104(4): 942-947.

PubMed Abstract | Publisher Full Tex

Duprez L, Wirawan E, Vanden Berghe T, et al:: Major cell death pathways at a glance. Microbes Infect. 2009; 11(13): 1050-1062.

PubMed Abstract | Publisher Full Text

Esparza J: A new scientific paradigm may be needed to finally develop an HIV vaccine. Front Immunol. 2015; 6: 124.

PubMed Abstract | Publisher Full Text | Free Full Text

Fowke KR, Nagelkerke NJ, Kimani J, et al:: Resistance to HIV-1 infection among persistently seronegative prostitutes in Nairobi, Kenya. Lancet. 1996; 348(9038): 1347-1351.

PubMed Abstract | Publisher Full Text
Gifford RJ: Viral evolution in deep time: lentiviruses and mammals. Trends Genet. 2012; 28(2): 89-100.

PubMed Abstract | Publisher Full Text

Gonzalez-Hernandez MJ, Swanson MD, Contreras-Galindo R, et al.: Expression of human endogenous retrovirus type $K$ (HML-2) is activated by the Tat protein of HIV-1. J Virol. 2012; 86(15): 7790-7805.

PubMed Abstract | Publisher Full Text | Free Full Text

Hartmann G: Nucleic acid immunity. Adv Immunol. 2017; 133: 121-169.

PubMed Abstract | Publisher Full Text

Held GA, Grinstein G, Tu Y: Modeling of DNA microarray data by using physical properties of hybridization. Proc Natl Acad Sci U S A. 2003; 100(13): 7575-7580. PubMed Abstract | Publisher Full Text | Free Full Text

Hütter S, Zurnic I, Lindemann D: Foamy virus budding and release. Viruses. 2013; 5(4): 1075-1098.

PubMed Abstract | Publisher Full Text | Free Full Text

Jaumdally SZ, Picton A, Tiemessen CT, et al.: CCR5 expression, haplotype and immune activation in protection from infection in HIV-exposed uninfected individuals in HIV-serodiscordant relationships. Immunology. 2017. [Epub ahead of print].

PubMed Abstract | Publisher Full Text

Jones RB, Garrison KE, Mujib S, et al:: HERV-K-specific T cells eliminate diverse HIV-1/2 and SIV primary isolates. J Clin Invest. 2012; 122(12): 4473-4489. PubMed Abstract | Publisher Full Text | Free Full Text

Karamitros T, Paraskevis D, Hatzakis A, et al.: A contaminant-free assessment of Endogenous Retroviral RNA in human plasma. Sci Rep. 2016; 6: 33598. PubMed Abstract | Publisher Full Text | Free Full Text

Katzourakis A, Tristem M, Pybus OG, et al.: Discovery and analysis of the first endogenous lentivirus. Proc Natl Acad Sci U S A. 2007; 104(15):

6261-6265.

PubMed Abstract | Publisher Full Text | Free Full Text

Kaul R, Rowland-Jones SL, Kimani J, et al.: Late seroconversion in HIV-resistant Nairobi prostitutes despite pre-existing HIV-specific $\mathrm{CD} 8^{+}$responses. $J$ Clin Invest. 2001; 107(3): 341-349.

PubMed Abstract | Publisher Full Text | Free Full Text

Khare R, Chen CY, Weaver EA, et al:: Advances and future challenges in adenoviral vector pharmacology and targeting. Curr Gene Ther. 2011; 11(4): 241-258.

PubMed Abstract | Publisher Full Text | Free Full Text

Kim YJ, Han K: Endogenous retrovirus-mediated genomic variations in chimpanzees. Mob Genet Elements. 2015; 4(6): 1-4.

PubMed Abstract | Publisher Full Text | Free Full Text

Laderoute MP: A new paradigm about HERV-K102 particle production and blocked release to explain cortisol mediated immunosenescence and ageassociated risk of chronic disease. Discov Med. 2015; 20(112): 379-391. PubMed Abstract

Laderoute MP, Giulivi A, Larocque L, et al:: The replicative activity of human endogenous retrovirus K102 (HERV-K102) with HIV viremia. AIDS. 2007; 21(18): 2417-2424.

PubMed Abstract | Publisher Full Text

Laderoute MP, Larocque LJ, Giulivi A, et al.: Further evidence that human endogenous retrovirus $\mathrm{K} 102$ is a replication competent foamy virus that may antagonize HIV-1 replication. Open AIDS J. 2015; 9: 112-122.

PubMed Abstract | Publisher Full Text | Free Full Text

Langergraber KE, Prüfer K, Rowney C, et al:: Generation times in wild chimpanzees and gorillas suggest earlier divergence times in great ape 
and human evolution. Proc Natl Acad Sci U S A. 2012; 109(39): 15716-15721. PubMed Abstract | Publisher Full Text | Free Full Text

Lee YN, Bieniasz PD: Reconstitution of an infectious human endogenous retrovirus. PLoS Pathog. 2007; 3(1): e10.

PubMed Abstract | Publisher Full Text | Free Full Text

Linial ML: Foamy virus replication: implications for interaction with other retroviruses and host cellular sequences. Dev Biol (Basel). 2001; 106: 231-236. PubMed Abstract

Magiorkinis G, Blanco-Melo D, Belshaw R: The decline of human endogenous retroviruses: extinction and survival. Retrovirology. 2015; 12: 8 .

PubMed Abstract | Publisher Full Text | Free Full Text

Meiering $\mathrm{CD}$, Comstock KE, Linial ML: Multiple integrations of human foamy virus in persistently infected human erythroleukemia cells. $J$ Virol. 2000; 74(4) 1718-1726.

PubMed Abstract | Publisher Full Text | Free Full Text

Morrison CS, Chen PL, Kwok C, et al:: Hormonal contraception and the risk of HIV acquisition: an individual participant data meta-analysis. PLOS Med. 2015 12(1): e1001778

PubMed Abstract | Publisher Full Text | Free Full Text

O'Neil SP, Novembre FJ, Hill AB, et al:: Progressive infection in a subset of HIV1-positive chimpanzees. J Infect Dis. 2000; 182(4): 1051-1062.

PubMed Abstract | Publisher Full Text

Ono M, Kawakami M, Ushikubo H: Stimulation of expression of the human endogenous retrovirus genome by female steroid hormones in human breast cancer cell line T47D. J Virol. 1987; 61(6): 2059-2062.

PubMed Abstract | Free Full Text

Ormsby CE, Sengupta D, Tandon R, et al:: Human endogenous retrovirus expression is inversely associated with chronic immune activation in HIV-1 infection. PLoS One. 2012; 7(8): e41021.

PubMed Abstract | Publisher Full Text | Free Full Text

Rerks-Ngarm S, Pitisuttithum P, Nitayaphan S, et al:: Vaccination with ALVAC and AIDSVAX to prevent HIV-1 infection in Thailand. N Engl J Med. 2009; 361(23): 2209-2220.

PubMed Abstract | Publisher Full Text

Romano CM, Ramalho RF, Zanotto PM: Tempo and mode of ERV-K evolution in human and chimpanzee genomes. Arch Virol. 2006; 151(11): 2215-2228.

PubMed Abstract | Publisher Full Text
Sawyer SL, Emerman M, Malik HS: Ancient adaptive evolution of the primate antiviral DNA-editing enzyme APOBEC3G. PLOS Biol. 2004; 2(9): E275.

PubMed Abstract | Publisher Full Text | Free Full Text

Shin SY: Recent update in HIV vaccine development. Clin Exp Vaccine Res. 2016; 5(1): 6-11.

PubMed Abstract | Publisher Full Text | Free Full Text

Siemion IZ, Kluczyk A: Tuftsin: on the 30-year anniversary of Victor Najjar's discovery. Peptides. 1999; 20(5): 645-674.

PubMed Abstract | Publisher Full Text

Stec M, Weglarczyk K, Baran J, et al:: Expansion and differentiation of CD14 ${ }^{+}$CD16 and $\mathrm{CD} 14^{++} \mathrm{CD} 16^{+}$human monocyte subsets from cord blood CD34+ hematopoietic progenitors. J Leukoc Biol. 2007; 82(3):

594-602.

PubMed Abstract | Publisher Full Text

Subramanian RP, Wildschutte JH, Russo C, et al.: Identification, characterization, and comparative genomic distribution of the HERV-K (HML-2) group of human endogenous retroviruses. Retrovirology. 2011; 8: 90.

PubMed Abstract | Publisher Full Text | Free Full Text

Tomaras GD, Plotkin SA: Complex immune correlates of protection in HIV-1 vaccine efficacy trials. Immunol Rev. 2017; 275(1): 245-261.

PubMed Abstract | Publisher Full Text | Free Full Text

Vincendeau M, Göttesdorfer I, Schreml JM, et al.: Modulation of human endogenous retrovirus (HERV) transcription during persistent and de novo HIV-1 infection. Retrovirology. 2015; 12: 27.

PubMed Abstract | Publisher Full Text | Free Full Text

Wang-Johanning F, Rycaj K, Plummer JB, et al.: Immunotherapeutic potential of anti-human endogenous retrovirus- $K$ envelope protein antibodies in targeting breast tumors. J Natl Cancer Inst. 2012; 104(3): 189-210.

PubMed Abstract | Publisher Full Text | Free Full Text

Yong MK, Cameron PU, Spelman T, et al.: Quantifying adaptive and innate immune responses in HIV-infected participants using a novel high throughput assay. PLoS One. 2016; 11(12): e0166549.

PubMed Abstract | Publisher Full Text | Free Full Text

Young GR, Mavrommatis B, Kassiotis G: Microarray analysis reveals global modulation of endogenous retroelement transcription by microbes.

Retrovirology. 2014; 11: 59.

PubMed Abstract | Publisher Full Text | Free Full Text 


\section{Open Peer Review}

\section{Current Peer Review Status: $\mathrm{X}$}

Version 1

Reviewer Report 27 November 2017

https://doi.org/10.5256/f1000research.12772.r26997

(C) 2017 Fast P. This is an open access peer review report distributed under the terms of the Creative Commons Attribution License, which permits unrestricted use, distribution, and reproduction in any medium, provided the original work is properly cited.

\section{Patricia E Fast}

${ }^{1}$ International AIDS Vaccine Initiative-New York, New York, USA

2 Pediatric Infectious Diseases, Stanford University School of Medicine, Stanford, CA, USA

Dr. Laderoute has advanced a novel and interesting hypothesis, that an innate immune state associated with the virus HERV-K 102 can, in some circumstances, prevent or reduce the risk of HIV infection by a mechanism of infection of macrophages and activation of innate immunity. Dr Laderoute also proposes that this mechanism can go wrong in such a way as to increase risk and finally that vaccination with HIV vaccine candidates can influence this interaction or vice versa. A number of facts or interpretations are marshalled to support this hypothesis.

The main weakness of the paper is that it discusses a proposed causal relationship but, at many points in the argument, mentions only one interpretation of existing data and ignores alternative explanations, even when there are reasonably strong data supporting those explanations (for example, the elegant demonstration of correlate of risks in RV144 described by Haynes, Kim, Tomaras, Zolla-Pazner and others).

The basic postulate proposed is that an endogenous retrovirus, HERV-K102 might interact with macrophages, particularly Kupffer cells, and that the innate immunity induced would temporarily (6 months) alter host susceptibility to HIV infection, in a way that could interact with HIV vaccine effects. Part of this argument is that 'macrophages' are involved in initiation or control of adaptive immune responses. However, the dendritic cells that are intimately involved in initiating immune responses, differ from Kupffer cells, and this difference is not discussed.

Hormonal influence on the HERV-K102 link to innate immune states are postulated because in efficacy trials of one HIV vaccine, there appeared to be a gender effect on the results (the difference in efficacy between women and men in RV144 was not statistically significant). In fact the exposure, risk factors and baseline incidence differed between men and women in the two trials of the Ad5-vectored vaccine, STEP and Phambili, and it cannot be concluded from those data alone that there is a hormonal influence on susceptibility, let alone that is linked to endogenous retroviruses. 
The cohort of highly-exposed female sex workers in Nairobi is also cited as potentially protected by transient innate immune mechanisms related to infection of macrophages with the endogenous virus. This putative immunity fades within months after the women cease sex work-it seems unlikely that a mechanism based on co-infection with HERV-K102 would be influenced by ending sex work or that the endogenous retrovirus infection somehow depends upon continued sex work. If the HERV-K102 virus-related mechanism fades after 6 months, that should be 6 months from the time of infection with the HERV-K102 virus (which is unknown), not 6 months after ceasing sex work.

No evidence is cited to link the virus infection itself or its interaction with macrophages to vaccination with HIV vaccines (a suggestion is made that the peptide tuftsin could be involved, but the link of tuftsin to HIV vaccines is not clear to me). To Dr Laderoute's credit, she points out that a direct examination of this prediction is needed to test the hypothesis.

In summary, the endogenous retrovirus is fascinating, and its potential interactions with HIV may be worthy of study. This is clearly an opinion paper, so some latitude in the discussion is permissible, but the paper does not make a sufficient case for its hypothesis. Highly selective interpretations of data in the literature have been made to link that virus with protection from HIV infection, and alternate explanations are not explored adequately. The postulated alteration of the effects of HIV vaccines on risk of infection requires several logical leaps, each of which has alternate explanations, and the range of evidence is not discussed in sufficient detail. The paper could be improved by limiting its scope and providing a much more comprehensive and balanced argument.

Is the topic of the opinion article discussed accurately in the context of the current literature?

Partly

\section{Are all factual statements correct and adequately supported by citations?}

No

Are arguments sufficiently supported by evidence from the published literature? No

Are the conclusions drawn balanced and justified on the basis of the presented arguments? No

Competing Interests: No competing interests were disclosed.

Reviewer Expertise: Vaccines, HIV epidemiology

I confirm that I have read this submission and believe that I have an appropriate level of expertise to state that I do not consider it to be of an acceptable scientific standard, for reasons outlined above. 


\section{Dr. Marian Laderoute, Immune System Management Clinic \& Lab, Canada}

First I would like to sincerely thank Dr. Patricia Fast for taking the time to read through this opinion-hypothesis paper as the concept of correlates of protection ('true' or not) against HIV-1 is vitally important for the derivation of HIV-1 prevention vaccines as well as cure. In hindsight, I wholeheartedly agree that I should have had more discussion on proposed correlates of protection from HIV-1 vaccine prevention trials and why these have been rejected by others and myself. This has been corrected in the revision and importantly includes a vigorous discussion on why adaptive immunity mechanisms are unlikely to prevent HIV-1 acquisition (i.e., the elephant in the room) substantiated directly by the finding that there is no evidence in humans to defend this approach. The concept that the HERV-K102 virus unique to humans represents a 'virus anti-virus response' (in this case a foamy retrovirus anti-lentivirus response) and is part of innate immunity which generates foamy macrophages, is hard to grasp because it is so revolutionary. So now I have made this point of it being a 'virus anti-virus response' crystal clear not only in the abstract, but in the introduction, and have also tried to present the concept of the HERV-K102 virus being anti-HIV-1 more clearly. I think this may be why publication in F1000 Research with its open review can be extremely valuable for the communication of completely novel, if not totally foreign ideas. As a writer, I have to know why readers are not 'getting it' so that I can try to explain the concepts better.

\section{A main weakness is the poor discussion of correlates of protection from HIV-1} vaccine prevention trials and only mentions one interpretation of existing data. The revision now incorporates a lengthy discussion of correlates of protection from HIV-1 vaccine prevention trials and why one must conclude that a surrogate correlate of protection or a 'true' correlate of protection protecting against HIV-1 acquisition has not been demonstrated in the HIV-1 vaccine prevention trials. Indeed, a true correlate of protection has not been convincingly demonstrated not only in HIV-1 vaccine prevention trials (over 200 attempts) but also in studies of HIV-1 exposed seronegative cohorts (Safrit \& Koff, 2016).

2. Macrophages such as Kupffer cells are distinct from dendritic cells (DCs) and Dr. Fast implies only DCs are involved in initiating immune responses. This difference was not discussed. According to a recent review article, developmental studies in mice suggest DCs originate independently from monocytes and tissue macrophages, and for a long time these subsets of antigen-presenting cells were thought to overlap (Collin M et al., Immunology 2013). However, both cell types are antigen-presenting cells and are still studied and are relevant in terms of activating innate and adaptive immunity as derived and studied from human blood (Sander J et al., Immunity 2017; Metcalf TU et al., J. Immunology 2017). Kupffer cells constitute 80$90 \%$ of the tissue macrophages in the body and are essential to innate and adaptive immunity (Li P et al., Molecular Immunology 2017). The point being made in the paper is that the Ad5 vector targets Kupffer cells (which are macrophages) and the foamy macrophages which appear to produce HERV-K102 particles are most likely CD14 positive (as elimination of the CD14 positive cells from cord blood mononuclear cells abrogated HERV-K102 particle production, the production of foamy macrophages, the accumulation of HERV-K102 CDNA and the increase in HERV-K102 pol gene copy number in genomic DNA (unpublished data)). These foamy macrophages are morphologically distinct from all others and resemble those produced under similar 
conditions from cord blood mononuclear cells by Stec M et al., (J. Leukocyte Biology, 2007) which were characterized as CD14++ CD16+ macrophages which showed enhanced expression of CD11b, HLA-DR and CCR5. CCR5 is critical to the HIV-1 story, and thus, foamy macrophages may be very relevant to the proposed protective innate mechanism. Gartner et al., (Science, 1986) were first to elucidate that acquisition of HIV-1 first involves infection of macrophages and this has been followed by many publications regarding the R5 versus X4 strains (eg. see reviews Arif MS et al., 2017; Naif HM, Inf Dis Rep 2013), wherein CCR5-tropic (R5) viruses are preferentially transmitted by all routes of infection (Shaw GM \& Hunter E, Cold Spring Harb Perspect Med 2012). The CD14++CD16+ monocytes express the highest levels of CCR5 than CD14++CD16- or CD14lowCD16+ and are preferentially infected by HIV (Ellery PJ et al., J Immunology 2007). In contrast it should be noted that DCs express CD4 but are poorly sensitive to HIV-1 infection (Chauveau L et al., J. Virol 2017). Moreover, SAMHD1 in DCs not only impacts HIV-1 replication but also antigen presentation (Ayinde D et al., J. Virol 2015). In a recent study involving humanized mice, it was the CD14+CD16+ monocytes/macrophages rather than CD14-CD16+ dendritic cells which increased during early infection and harbored integrated HIV-1 DNA such as found in spleen (Arainga $M$ et al., Sci.Reports 2016). It is the monocyte/macrophage which serves as a viral reservoir during HIV-1 infection (Arainga $\mathrm{M}$ et al., Retrovirology 2017). Accordingly, the issue of dendritic cells versus macrophages was not discussed as DCs may not be so relevant to HIV- 1 infection and pathogenesis. However, in fairness, it has been suggested in mucosal studies that the vaginal myeloid dendritic cells may transmit founder HIV-1 (Shen et al., 2014).

3. Gender differences on VE in the HIV-1 prevention vaccine trials was only shown in one of two trials. There were insufficient HIV-1 infections in the STEP trial to calculate VE. The difference in VE between women and men in RV144 was not statistically significant. While the authors (Rerks-Ngarm et al., NEJM 2009) state that subgroup analyses revealed no significant heterogeneity in vaccine efficacy according to baseline variables (Table 2 ), $p$ values were not provided for the subgroup analyses in Table 2. A discrepancy between the MITT VE 95\% CI reported in Table $2(n=15,948)$ and the abstract $(n=16,395)$ was noted for "all subjects" whereby in the analyses of Table 2 there were 447 less participants (missing 237 in the vaccine arm of which 158 were male and 210 in the placebo arm of which 146 were male, from Table 1). Potential discrepancies in the lower and upper boundaries of the $95 \%$ CI reported for the two subgroup analyses by gender when compared with all subjects particularly the lower boundary (negative values for each of the sex subgroups but positive for the 'all subjects' category) might imply an error was made in the reported CIs. For example, it might be possible that the lower boundary for the $\mathrm{CI}$ of the female subgroup analysis might have been positive, suggesting statistical significance. Accordingly, a VE of $38.6 \%$ in the female subgroup when compared with $25.8 \%$ in the male subgroup may or may not have been statistically significant and needs further clarification. Nevertheless, presently, one could refer to this finding as a trend towards potential significance. This fine point has been rectified in the revision.

4. There is no evidence from the vaccine prevention trials that endogenous retroviruses are hormonally regulated or that susceptibility to HIV-1 infection is influenced by HERVs. This is correct because it was not tested. The point being made 
is to test for HERV-K102 particles and/or integration levels by gender subgroups (and by type and use of contraceptives) to characterize if HERV-K102 might be involved as a correlate of protection.

5. Co-infection with HERV-K102, the time of infection which is unknown, cannot explain why in an HESN cohort involving sex work this putative innate immunity could fade such as by $\mathbf{6}$ months by ending sex work. There is no co-infection of the host by HERV-K102 as it is not an exogenous virus. The induction of HERV-K102 virus which is unique to humans, is a host 'virus anti-virus' response. The HERV-K102 virus located on chromosome 1 is found in all humans. It becomes active and produces particles in large numbers of foamy macrophages in response to viruses (Laderoute et al., AIDS 2007; Open AIDS J, 2015). Elite controllers have strong cellular and antibody responses to HERV-K HML-2 Gag (de Mulder M et al., Retrovirology 2017) not present in viremic non-controllers nor healthy controls. While particles can be made at extremely high levels in patients with infected with blood borne pathogens (commonly up to $10^{11}$ particles per $\mathrm{ml}$ of plasma), in patients with HIV-1 infection the mean particle production is around 8,300 particles per $\mathrm{ml}$ (maximum levels are 6-7 logs reduced) and is found in about $72 \%$ of HIV-1 patients. In the Nairobi HESN cohort, evidence of past high levels of HERV-K102 particle production was provided by showing on DNA isolated from plasma, that the mean genomic copy number was significantly ( $p=0.0005$ ) elevated by about 5 fold above controls (the latter shown not to have any HERV-K HML-2 particles in plasma including HERV-K102). Increased integration was not found in HIV-1 infected patients (which were not statistically different from uninfected healthy controls). There can be a very rapid induction of large numbers of HERV-K102 particles in vitro and in vivo, the latter reaching $2.55 \times 10$ 11 particles per $\mathrm{ml}$ of plasma in 84 hours. Studies by others have shown that antibodies to HERV-K HML-2 antigens wane within 6 months with germ cell tumor remissions (Kleiman A et al., Int J Cancer 2004). In the absence of exposure to pathogens (or cancer), the stimulus for HERV-K102 particle production and thus antibody/T cell responses might wane, consistent with findings in normal healthy controls as reported by many groups. Thus, the finding by Kaul et al, 2001 that resistance to HIV-1 acquisition fades as early as 6 months following sex work interruption in the Nairobi HESN cohort could be related to decreased HERVK102/HML-2 activation due to lack of stimulation by or exposure to intracellular microbes.

6. No evidence is cited to link the virus infection itself (HERV-K102) or its interaction with macrophage to vaccination with HIV vaccines. There is no exogenous infection for an endogenous retrovirus. It is proposed that vaccination with viral vectors used in the 3 informative HIV prevention trials and not those lacking vectors for the priming may be analogous to exposures to viruses which might preferentially activate HERV-K102 particle production along with HML-2 activation over adaptive immunity. There seems to be reciprocal activation of adaptive immunity with the HERV-K102/HML-2 response. For example, in vitro, the addition of PHA and IL-2 has been shown to completely block HERV-K102 particle production under conditions permissive for HERV-K102 particle production (i.e., culture in IMDM and not RPMI media, more than a dozen replicates unpublished data). Similarly culture in RPMI blocks HERV-K102 particle production (unpublished observations) but allows adaptive immunity mechanisms (see also Argaw-Denboba et al., 2017 for 
HERV-K activation interference). As well, RNA for HERV-K MHL-2 gag and env was found to be inversely correlated with $T$ cell activation markers when tested on PBMCs from HIV-1 patients, also implying an inverse correlation of HML-2 responses with adaptive immunity. Moreover as discussed in the revised manuscript, there were non-specific effects of the viral vectors unrelated to HIV-1 antigen specificities (STEP, Huang et al., 2014; STEP, Migueles et al., 2011, and see discussion in Tomaras \& Plotkin, 2017).

Competing Interests: I am the author of the article and am responding to the objections raised by Dr. Fast. I have no competing interests except that HERV-K102 particles and HML-2 responses should be investigated in HIV-1 vaccine prevention trial participants which is why I wrote the article and now have revised it.

The benefits of publishing with F1000Research:

- Your article is published within days, with no editorial bias

- You can publish traditional articles, null/negative results, case reports, data notes and more

- The peer review process is transparent and collaborative

- Your article is indexed in PubMed after passing peer review

- Dedicated customer support at every stage

For pre-submission enquiries, contact research@f1000.com 